\title{
The London Sports Medicine Institute
}

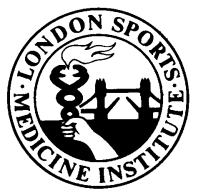

\section{Hilary Williams, General Secretary}

The London Sports Medicine Institute (LSMI) is a unique charity. The idea for the LSMI came from Dr Dan Tunstall Pedoe's involvement with the London Marathon. Chris Brasher who organizes the Marathon introduced Dr Tunstall Pedoe to Peter Pitt who was then Chair of the Greater London Council Arts and Recreation Committee. Two years later, after lengthy negotiations, the LSMI was founded in February 1986 with a grant from the GLC to support its three main objectives:

- To promote research and teaching in sports medicine.

- To establish a library and database.

- To act as a centre for sports medicine in London.

Until the LSMI was founded there was no centre for sports medicine in Britain.

The LSMI premises are leased from the medical college of St Bartholomew's Hospital in Charterhouse Square, and the following facilities are available: research library, seminar and teaching room, physiological testing laboratory, clinical examination and changing rooms, and offices.

There are currently nine people working at the LSMI: general secretary-Mrs Hiliary Williams, medical director (part time)- Dr Dan Tunstall Pedoe, administrative secretary-Mrs Susan Riches, research physiologistDr Andrew Head, research physiotherapist-Miss Wendy Green, librarian-Miss Kathryn Walter, YTS trainee-Mr Tony Blake, BASM education officer-Ms Nancy Laurenson, Sports Nutrition Foundation administrator-Mrs Catriona Greaves.

\section{Education}

Sports medicine has hithero received no official recognition as a specialized branch of medicine in the United Kingdom. However, the Society of Apothecaries announced in December
1988 that they would be offering a Diploma in Sports Medicine and that the first examination will take place in June 1989. This examination gives recognition to the courses in sports medicine being run by the LSMI, BASM and the London Hospital.

The LSMI three year part-time course for general practitioners is designed to provide both a background in human exercise physiology, and practical information about the prevention and treatment of sports injuries. Lectures, practical sessions and tutorials take place on Wednesday evenings at the LSMI. There are currently 25 general practitioners enrolled on the course, many of whom are already heavily involved in sports medicine as medical officers to professional and amateur sports clubs.

\section{Lecture series}

A series of lectures is organized in conjunction with the course for general practitioners. Audience numbers for these lectures has increased from 30 in
1987 when the series started, to over 100 in the Autumn term 1988. Admission to the lectures is free and if you would like your name to be added to the LSMI's mailing list please let us know and you will then receive details of forthcoming events.

\section{Annual guest lecture}

Since 1986 the LSMI has invited a distinguished guest speaker from overseas to give a lecture in London. The lecture in 1986 started the education programme and was given by Professor William Morgan (University of Wisconsin-Madison, USA) entitled 'Exercise and psychic state-elation or depression. Is exercise good for the mind?' The 1987 lecture by Professor David Costill (Ball State University, Indiana) on "Training trauma-optimal training for maximal sports performance' attracted an audience of over 200 and was described by Chris Brasher in an article in the Observer as 'one of the most important lectures I have ever attended'. In 1988, Professor Ejnar

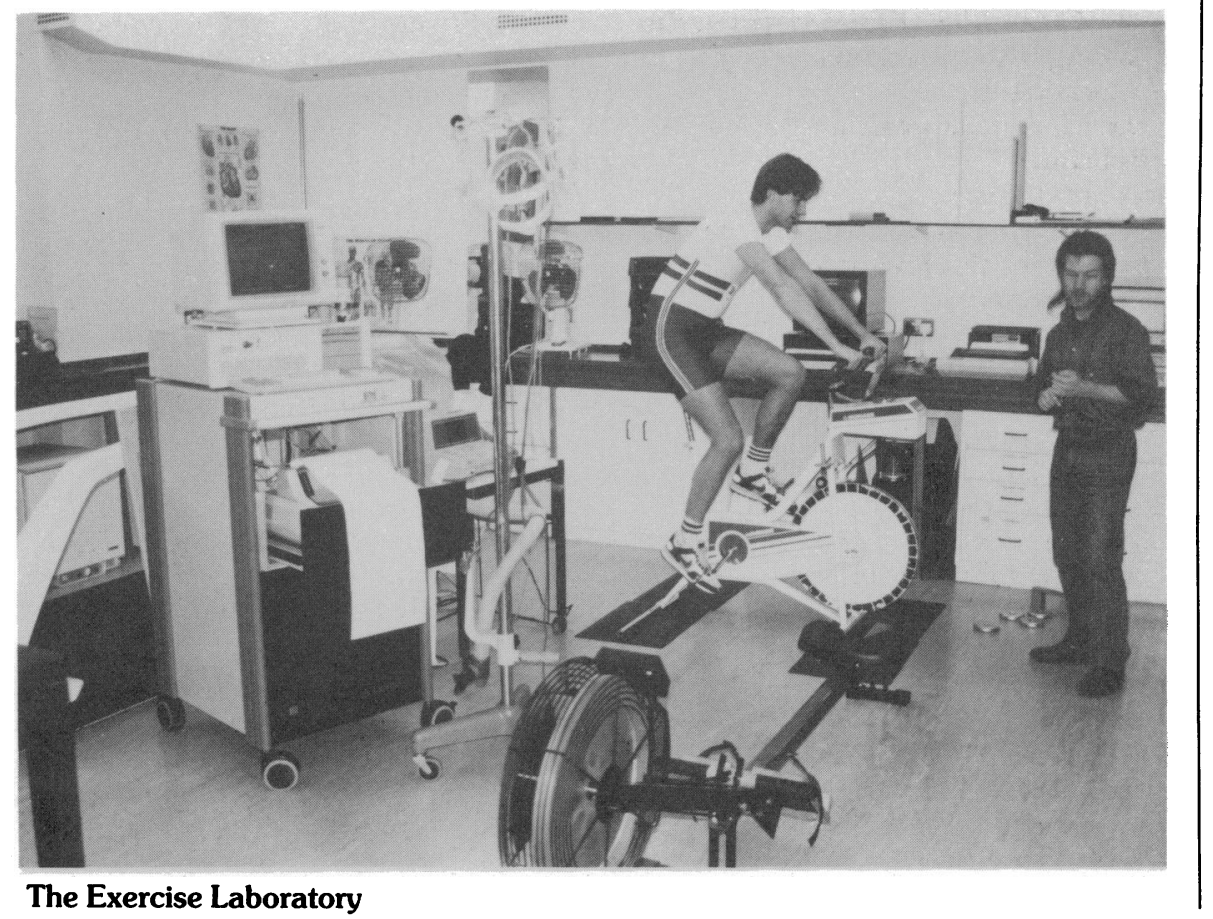


Eriksson (Karolinska Hospital, Stockholm) gave his lecture on "Training to destruction-overuse injuries of the lower extremity in sport'.

\section{Research and teaching}

The physiological testing laboratory is equipped for research, teaching and fitness testing. The equipment includes cycle and rowing ergometers, a treadmill and a computerized system for both the measurement of $\mathrm{V}_{\mathrm{O}_{2}}$ max and the Wingate strength and power test. Also available are a lactate analyser and a twelve lead ECG heart rate monitor.

The laboratory is used to provide demonstrations to various groups interested in sports medicine including general practitioners taking part in the LSMI course on sports medicine, medical students from St Bartholomew's Hospital medical college, MSc students from King's College London, and students taking the one year diploma course at the London Hospital.

Research projects carried out in the laboratory have included:

- The role of endorphins in the cardiorespiratory and hormonal responses to exercise.

- The effects of different carbohydrates on endurance performance in trained runners and rowers.

- A comparison of potential indices of endurance fitness.

- Exercise induced dehydration in senior oarsmen-does it occur and does it limit perfomance?

The laboratory is also used for fitness testing purposes. During 1989 we will be testing the lightweight men's and women's national rowing squads.

\section{Library and information services}

The library is open from 9.00am$5.00 \mathrm{pm}$ Monday to Friday. There is a steady stream of visitors to the library

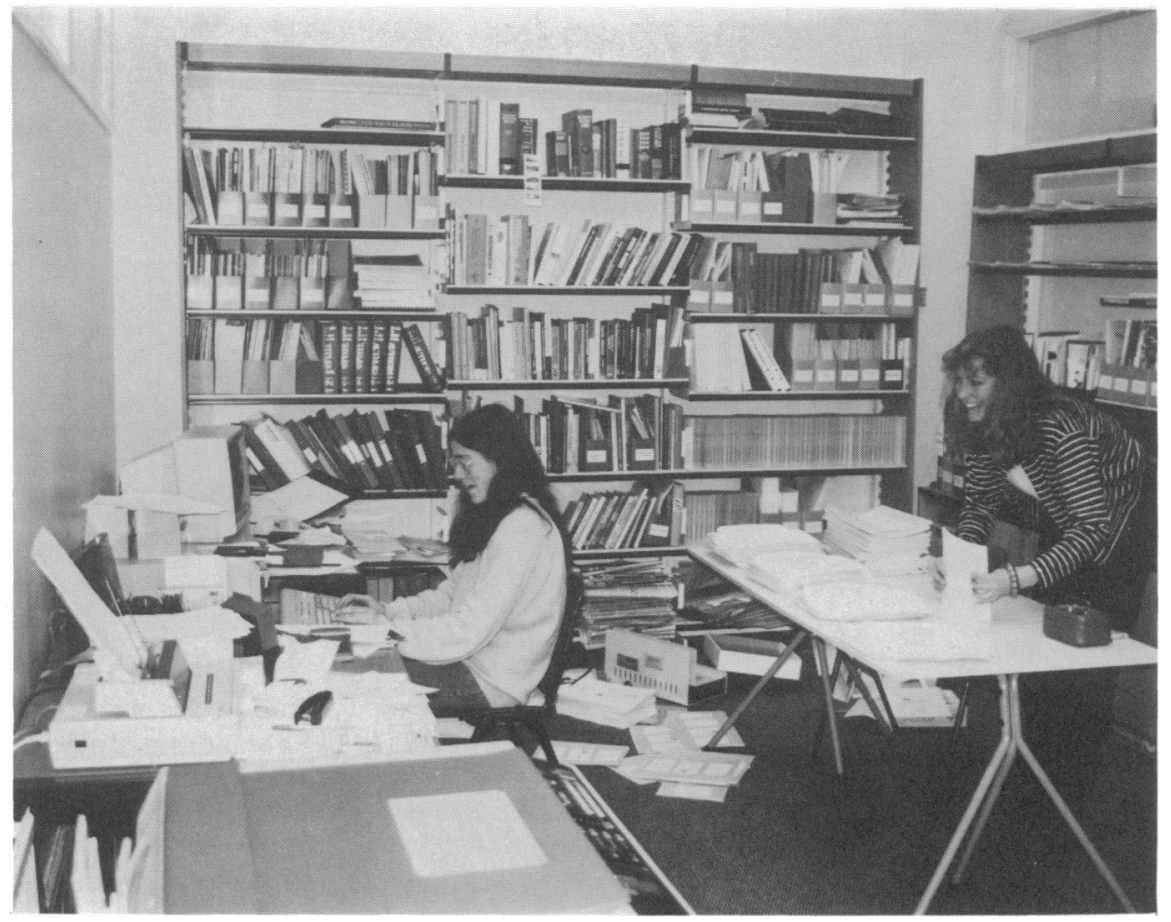

\section{The Library}

which deals both with requests for information on general sport related topics from the public and specialist requests which require literature searches-either on our own in-house database or using external databases e.g. Medline and Sport.

Since 1986, the journal and book stock has been built up so that now the library takes 75 journals, many with a substantial backrun together with a collection of monographs. We have also built up a collection of pamphlets, annual reports and reference works. Copies of the journals holding list and recent book accessions lists can be obtained from the library. As part of the information service, the LSMI produces a list of sports injury clinics in the London area. The list gives details of specialists treatments, opening times and charges.

The current awareness service provided by the library include a monthly bibliography entitled Sports Medicine Bulletin. There are subscribers to the bulletin both in the UK and overseas and the library is currently dealing with in excess of 150 requests a month for photocopies of articles listed in the bulletin. In addition, a series of specialist bibliographies are available. These are published bimonthly and the current titles are Sports Nutrition, Sport Physiotherapy and Ergogenic Aids in Sport. Subscription details for the Sports Medicine Bulletin and specialist bibliographies are available from the librarian.

Since the LSMI was founded in 1986, real progress has been made towards fulfilling the three objectives of promoting research and education, establishing a library and database and providing a centre for sports medicine. We hope to continue the programmes that we have established and from now onwards there will be the need to raise future of the London Sports Medicine Institute and its unique role in sports medicine. sufficient funds to ensure the long term 